\title{
Engineering education, research and design: breaking in and out of liminal space
}

Accepted for publication in the

Journal of Professional Issues in Engineering Education and Practice

Andrew T.M. Phillips MEng PhD MEd DiC CEng MIMechE FHEA

Imperial College London, Department of Civil and Environmental Engineering, Skempton Building, South Kensington Campus, London SW7 2AZ

andrew.phillips@imperial.ac.uk | orcid.org/0000-0001-6618-0145

ABSTRACT

Liminality is presented as a concept familiar to engineering educators, researchers and designers, as a state of challenge and discomfort that we must flux in and out of in order

4 to advance our respective aims. Common areas for discussion in familiarising engineering 5 learners with liminality are sought. Threshold concepts, divergent-convergent thinking, and

6 the concept of design, research and education as iterative processes associated with breaking

7 in and out of liminal space are explored. The duality of learning is discussed through the acquisition and participation metaphors. The use of design courses in leading learners in to and out of liminal space, and in particular the Group Design Projects on the Imperial 10 Civil Engineering MEng degree are discussed. In closing the informed creative, as opposed characterised, along with the skills and experiences that the engineering community would wish engineering graduates to have. 


\section{INTRODUCTION}

The development of the ability to design is viewed as the distinguishing feature of an engineering education in Britain, Europe and North America. This study argues that the concept of liminality may be beneficially applied to the practices of engineering education, research and design. Each of these areas of practice can be viewed as an iterative rather than a linear process, where the participants become comfortable with fluctuating in and out of liminal space. Effective practitioners, engineering academics, students, researchers and designers must be capable of this transition, not allowing themselves to exist either fully in the world of knowledge and understanding, or in the world of creativity and fantasy. Engineers must in effect be the dreamers of the day.

Those who dream by night in the dusty recesses of their minds wake in the day to find that all was vanity; but the dreamers of the day are dangerous men, for they may act their dream with open eyes, and make it possible. (T.E Lawrence)

This is not to suggest that engineers should develop dangerous as opposed to safe designs, but rather that engineers should be comfortable with the uncomfortable process of converting innovative ideas into practical realities. 'Dangerous men' are those women and men who are effective in achieving this. Breaking in and out of liminal space may be considered as the iterative process by which engineers deliberately take themselves out of their comfort zone at different stages of the design process, to strive for design excellence, as opposed to routine design, that can develop through adherence to familiar approaches. Liminality can be considered as a state of ambiguity, in which the engineer tolerates and even encourages a diverse range of potential design outcomes, resolving on the optimal solution during the design process.

This study examines education, research and design within the context of the author's experiences as a lecturer and researcher in the Department of Civil and Environmental 
Engineering at Imperial College London. In particular drawing on experiences of supervising $\mathrm{PhD}$ students, individual MSc and final year MEng project students, delivering first and second year Structural Mechanics, and in coordinating the Group Design Projects in the third year of the four year Civil Engineering MEng degree.

In Britain MEng undergraduate degrees were introduced in the 1990s in response to a desire to raise the minimum standard required of engineering graduates going on to become Chartered Engineers to master's level, with a requirement for a significant research component. While many universities continue to run BEng undergraduate degrees, the majority of engineering institutions require graduates from these courses to complete an MSc or equivalent before following the standard route to becoming a Chartered Engineer. To meet the educational requirements to become a Chartered Engineer with one of the engineering institutions MEng degree courses in Civil Engineering must be accredited by the Joint Board of Moderators (JBM), comprised of representatives from the Institution of Civil Engineers, the Institution of Structural Engineers, the Chartered Institution of Highways and Transportation and the Institute of Highway Engineers.

Specific educational requirements leading to registration as an engineer vary across different countries in Europe, but in general require a period of university level study for a minimum of five years. Following the introduction of the Bologna process this period of study is frequently split into three years to obtain a bachelor's degree and two years to obtain a master's degree including a significant research component.

In a similar manner education requirements to register and practice as an engineer in the United States vary from state to state with reciprocity agreements existing between some states, but in general require completion of a bachelor's degree accredited by the Accreditation Board for Engineering and Technology (ABET).

In Britain the guidelines for the Accreditation of Higher Education Programmes set out 
by the Engineering Council (EC) (2014) state:

\begin{abstract}
Engineering ... is concerned with the art and practice of changing the world we live in. Driven by the needs of business and society, engineers strive to find solutions to complex challenges.
\end{abstract}

The EC document focuses on learning outcomes rather than inputs, and defines general and specific learning outcomes outcomes for engineering. General learning outcomes are considered to be knowledge and understanding; intellectual abilities including 'creative and innovative ability in the synthesis of solutions and in formulating designs'; practical skills including 'evidence of group working and participation in a major group project'; and transferable skills including 'problem solving, communication and working with others'. Specific learning outcomes are considered to be underpinning science and mathematics appropriate to the relevant engineering institution; engineering analysis; design, including the ability to 'define a problem'; economic, social and environmental context; and engineering practice. While the guidelines developed by the Engineering Council are informed by the 'required skills, knowledge and understanding ... set by a profession'. The guidelines set out by ABET (2016) in the United States place a similar emphasis on learning outcomes or abilities rather than inputs, similar to those set out by the Engineering Council, with intellectual abilities, practical and transferable skills common to all engineering disciplines and additional learning outcomes depending on the particular engineering discipline. Emphasis is placed on a 'an ability to function on multidisciplinary teams' as well as 'the broad education necessary to understand the impact of engineering solutions in a global, economic, environmental, and societal context' and 'a recognition of the need for, and an ability to engage in life-long learning'.

The EC and ABET approach of setting attribute based learning outcomes rather than specific knowledge inputs is admirable in its contrast to the approach of setting learning 
outcomes based on curriculum inputs. It is evident from the EC and ABET guidelines, discussion with colleagues and industry leaders that the characteristic that is most prized in graduating engineering students, at master's level, is the ability to design using an informed creative approach. This study looks at how this approach can be encouraged through the concept of liminality and its congruency with the desired education and research outcomes for master's students. It is suggested that there are a number of similarities between several educational and research, and creative and design narratives. The argument presented is that engineering benefits from scientific and artistic influences, and that failure to acknowledge both of these influences can result in uninspired, unachievable, or unsustainable design.

\section{METAPHORS, THRESHOLD CONCEPTS AND LIMINAL SPACE}

Within research active university engineering departments a tension can often be found between those faculty who are research active and tend to lecture on technical modules and those faculty or industry collaborators who are not research active and tend to facilitate design projects. It is proposed that the aim of encouraging learners to break in and out of liminal space can act as bridge between these two faculty groups, as it has application in gaining knowledge and understanding of complex and often abstract technical concepts as well as in the creative design process, which by necessity requires mastery of technical concepts to deliver realisable solutions.

The concepts of scientific knowledge and understanding, and artistic creativity and design have similarities to the acquisition and participation metaphors described by Sfard (1998). It is evident that understanding and design in particular require crossing and spanning between the two metaphors, with students encouraged to enter a liminal state when engaging with new concepts and methods of practice. Sfard argues that learning theories can be split between the acquisition metaphor $(\mathrm{AM})$ and the participation metaphor (PM) suggesting that 'too great a devotion to one particular metaphor can lead to theoretical distortions 
and to undesirable practices'. The acquisition metaphor is associated with the idea that understanding can be achieved through the accumulation of basic blocks of knowledge which can be constructed to form cognitive structures allowing concept development. There is the sense that the learner becomes the owner of the blocks of knowledge. It is implied therefore that the teacher is the original owner of the blocks of knowledge and it is in their power to pass these to the learner. It is left unclear as to how the learner is to assemble the blocks of knowledge to form conceptual understanding. Lecturing to large numbers of students, with little opportunity to break from the transmission mode of teaching (Chandler 1994), can be seen to be the AM enacted. Sfard (1998) highlights that with the AM alone we are left with a 'learning paradox' whereby the generation of new knowledge and understanding is inherently impossible. In higher education the AM may explain the acquisition of knowledge but it cannot account for the process of conceptual understanding, which requires students to enter a period of uncertainty or liminality.

The participation metaphor is associated with the idea of learning through participation in a community, with those new to the community being on the periphery, progressing towards the focus as their experience develops. The PM fits well with educationalist theories such as 'communities of practice' and 'situated learning' as proposed by Lave and Wenger (2003). While with the AM we are left with the question of how the learner is to form conceptual understanding from blocks of knowledge, with the PM we are left with the question as to how the blocks of knowledge form. It is important to note that while Lave and Wenger refer to learning they seldom refer to knowledge and understanding and the communities of practice to which they refer are those in which certain behaviours, as opposed to cognitive understanding, are required. Communities of practice observed by Lave and Wenger may not be representative of the professions including law, medicine and engineering, although they may viewed as being composed of professionals in the disciplines studied. Interestingly Sfard (1998) states that the PM '... entails, above all, the ability to communicate in the language of the community and act according to its particular norms'. 
This seems to imply that some form of knowledge must be acquired in order to reach even the periphery of a profession, with individuals required to clear a knowledge barrier prior to becoming participants. The limitation of the PM with regard to individual learning is also commented on 'How do we account for the fact that learners are able to build for themselves concepts that seem fully congruent with others? Or to put it differently how do people bridge individual and public possessions'. The PM requires learners and teachers as a community to enter liminal space in the discussion of concepts to develop a consistent understanding.

Transitioning from the AM to the PM can be an uncomfortable process for many students and faculty, requiring them to enter a liminal space, that they can emerge from, having appreciated the need for skills and attributes to facilitate participation, in addition to individual and shared knowledge and understanding. The AM and the PM are considered to be at odds with each other, much as technical modules and design projects can cause tension between different faculty groups, however this is only the case if they are each reduced to the absurd. In practice both learners and teachers will adopt either metaphor, and others as is appropriate and convenient depending on the situation. At a practical level engineering academics are often either unaware of the education theories that surround their practice, or are comfortable to view them as complimentary theories, at ease with utilising those parts that seem to be relevant, and ignoring those that do not. In this respect academics demonstrate a liminal trait, being comfortable with conflicting ideas, reinterpreting them to fit their own reflective narrative. It is clear that both the AM and PM have particular resonance in learning and understanding, but it is contended that neither provide clear insight into the creative spark, that coupled with knowledge and understanding, allows for engineering design thinking (Dym et al. 2005). The introduction of the concept of liminality and the ability to break in to and out of liminal space, transitioning rapidly between the AM and PM, provides the distinguishing feature of design excellence.

Observing the structure of the four year MEng course at Imperial, which is similar to 
many other Civil Engineering courses in Britain (Stratford 2016), the first and second years of the course are focused on the AM, while the third and fourth years are more focused on the PM; the abbreviations of the metaphors may not be merely coincidental. Lectures, that account for the majority of staff-student contact time, are primarily the AM. However even within a lecture, once a question is asked there is a sense of the PM, something beyond the pure transmission of information. Lectures provide the building blocks, although not the method of assembling a conceptual understanding from them. Developing their own understanding of complex concepts can be an uncomfortable and challenging experience for students, requiring them to break in to and out of liminal space, in order to be rewarded with knowledge beyond that of mere memory. The PM comes into play even in the first and second years of the MEng course in the form of tutorials, laboratories and project work. It is at this stage that the approach of the academic can be critical as to whether students begin assembling their own understanding, or whether they merely acquire more knowledge blocks. The PM is advanced in the third year with the six-week Group Design Projects. While developing individual understanding can be a struggle for some students, for others participating in the design process as a group member presents a similar uncomfortable and challenging experience. Here the concept of breaking in and out of liminal space provides a strategy for transitioning between different stages of the design process as well as researching unfamiliar processes. In the fourth year of the MEng course the individual research project requires students to challenge themselves in conducting research to a depth not covered in any of the technical modules. Central to the argument that the concept of liminality can be applied to the AM and PM is acceptance that one of the aims of a university education is to teach students how to learn. The role of the educator in the AM is to lead the learner in to and out of liminal space, while in the PM learners and educators must enter and exit liminal space as a shared endeavour. It is as we move from educationalist theories to academic practice that the notion of threshold concepts, as discussed by Meyer and Land (2003, 2005) and Cousin (2010), becomes useful as a way of engaging academics, students, and 
educationalists.

Meyer and Land (2003) describe a threshold concept as associated with troublesome knowledge as described by Perkins (1999). They comment that 'A threshold concept can be considered as akin to a portal, opening up a new and previously inaccessible way of thinking about something. It represents a transformed way of understanding, or interpreting, or viewing something without which the learner cannot progress ... Such a transformed view or landscape may represent how people "think" in a particular discipline, or how they perceive, apprehend, or exercise particular phenomena within the discipline'. From the author's experience of teaching Structural Mechanics to first and second year MEng students, and Structural Analysis to MSc students, as well as in formulating research questions in Structural Biomechanics, there are two areas that may be considered to be threshold concepts. The first is that of tensors including second order tensors such as stress and strain. The second is in interpreting structural mechanics and solid mechanics theories to allow transition between the two. Threshold concepts can require students to struggle as they flux in and out of liminal space, assimilating and accommodating new knowledge and understanding, while reflecting on previous limitations. Once these thresholds have been crossed a transformative way of thinking is opened up, allowing problems to be formed and framed in a way that was not possible before. It allows the progression beyond ritual knowledge, which can have ' $a$ routine and rather meaningless character' (Perkins 1999), towards having tacit knowledge or understanding.

Meyer and Land (2003) also touch on discipline specific troublesome language, stating 'Language itself, as used within any academic discipline, can be another source of conceptual troublesomeness'. In engineering alternative forms of notation, such as sketches and flow charts, are used in addition to written text. Once made familiar to students these can be useful forms to communicate ideas and motivate them to break in and out of liminal space. These forms should be introduced within undergraduate engineering courses from 
the outset, as noted by Stratford (2016) reporting on design experiences on the University of Edinburgh Civil Engineering MEng degree. Meyer and Land (2005) extends previous work (Meyer and Land 2003) and looks in greater depth at threshold concepts within epistemological considerations, building towards a conceptual framework for teaching and learning. They comment that having engaged with and understood a threshold concept 'there occurs ... a shift in the learner's subjectivity, a repositioning of the self'. The concept of liminality is explored more fully as a period when a previous understanding is not yet fully dispensed with, while new understanding is not yet fully formed. Comparisons are made in Western society to adolescence which 'often involves oscillation between states of childhood and adulthood. Adolescence may be a protracted liminal state and may involve behaviours approximate to adulthood but constitute for a given period a form of mimicry of the new status'. Liminal space, as with adolescence can be seen as uncomfortable, and often the learner will have to relinquish some of their initial reluctance to enter it. The offer of a transformed understanding can act as an incentive to embrace liminality for a period of time before a knowledge or understanding transformation takes place. It is the cyclic breaking in and out of liminal space that should be considered to be the distinguishing characteristic of engineering designers, researchers and educators, and the desired characteristic that we wish to see in our master's and doctoral students.

Cousin (2010) studies liminality and threshold concepts in the context of research partnerships, in place of compartmentalised teacher-centred or student-centred learning. It is commented 'One of the difficulties teachers have is that of retracing the journey back to their own days of "innocence", when understandings of threshold concepts eluded them in the early stages of their own learning'. Clear parallels can be drawn between teacher-centred environments and the AM, and student-centred environments and the PM. The identification of threshold concepts forces engineering academics to revisit the way in which they developed their own conceptual frameworks. Experience in developing a number of tutorial sessions and laboratories indicates that it is through participation that students develop 
their own conceptual frameworks. This chimes true from speaking to current students, as well as the author's own experience both as a student and as a researcher. However these frameworks cannot be developed unless we have the building blocks with which to construct them. The notions of threshold concepts and liminal space are very appealing as it moves discussion away from educationalist theories, towards academics' knowledge and experience of their own subjects. However, more than just a way to engage academics they can be taken as a way of encouraging informed creativity. In discussing threshold concepts Cousin sees them as transformative, irreversible, integrative, troublesome, and associated with liminality. They are also described as bounded, although distinct may be a better term. The majority of academics will recognise these descriptions as applying to the development of their own conceptual frameworks, in particular the feeling of liminality. It can be seen as the responsibility of engineering academics and collaborating industry based engineering designers to lead students into this unstable space, encouraging them to struggle and emerge from it through active participation. As educators we should be more transparent with students both on technical modules and design projects about the motivation for entering and exiting liminal space. It may be the ease with which educators, researchers and designers do this that has meant that for the most part we have not felt the need to highlight this attribute to learners.

Design projects can be considered as an exercise to encourage or even force students into entering liminal space, with the design of an object or scheme allowing them to exit at the end of the exercise. There is increasing use of design projects on MEng engineering courses in Britain, both in the third and fourth years, and in the first and second years.

\section{DESIGN AND LIMINAL SPACE}

Several British universities, including Bath (Ibell 2016; Evernden et al. 2013; Ibell 2010), Edinburgh (Stratford 2016; Furber et al. 2014) and Manchester (Gillie et al. 2015) have in- 
vestigated and advocated the introduction of design activities and projects on courses leading towards engineering master's level qualifications, with Bath, Edinburgh, Leeds, Sheffield and others offering combined engineering and architecture degree courses. While the ability to rapidly enter and exit liminal space is not extensively mentioned in these studies, this is the defining feature of successful design processes, and the characteristic that is bought about in students undertaking design projects. Although focused on the North American higher education system, much of the work of Dym and his colleagues is relevant to the British system, with many aspects of engineering education being similar across North America, Britain and Europe (Dym 1999; Aparicio and Ruiz-Teran 2007).

\section{Design in engineering degrees}

Dym (2005) begins with the premises that 'the purpose of design education is to graduate engineers who can design, and that design thinking is complex'. The phrase 'design thinking' as used by Dym conveys a similar sense to the phrase 'informed creativity' adopted in the this study. In North America as well as Britain engineering education underwent a period of change, where there was a move away from traditional engineering apprenticeships towards teaching of core engineering science (Dym et al. 2005; Aparicio and Ruiz-Teran 2007). This was followed by a perception in both academia and industry that engineering students struggled to transfer theory to practice upon graduating. One response to this was the introduction of what Dym refers to as capstone design courses in later years of degrees. Another was the introduction of what Dym refers to as cornerstone courses in the early years of degree courses. It should be noted at this point that Imperial has separate departments for the study of engineering disciplines, of which the Department of Civil and Environmental Engineering is one. In this respect Imperial has not adopted the system common in many North American universities and some universities in Britain, such as Cambridge, of having a two year general course in engineering sciences before specialising in a particular discipline. However it is clear within the structure of the Civil Engineering MEng course at Imperial 
that core knowledge and understanding is primarily developed in the first and second years while design and creativity are increasingly focused on in the third and fourth years. Dym notes that 'Though the presence, role, and perception of design in the engineering curriculum have improved markedly in recent years, both design faculty and design practitioners would argue that further improvements are necessary'. In this statement Dym draws attention to the discourse that can occur between research faculty and design faculty. In a similar way that threshold concepts may provide a common ground between faculty, students and educationalists, the concept of moving in and out of liminal space can provide common ground between designers, researchers and educational practitioners including design and research faculty. Dym asks what is meant by design and provides the response:

Engineering design is a systematic, intelligent process in which designers generate, evaluate, and specify concepts for devices, systems, or processes whose form and function achieve clients' objectives or users' needs while satisfying a specified set of constraints

Design is something beyond mere problem solving. However some of the techniques recommended for problem solving (Felder and Silverman 1988; Stice 2004; Adams et al. 2007) may act as gateways into the design process. Dym (2005) characterises good designers as having the ability to 'tolerate ambiguity that shows up in viewing design as inquiry or as an iterative loop of divergent-convergent thinking; maintain sight of the big picture by including systems thinking and systems design; handle uncertainty; make decisions; think as part of a team in a social process; and think and communicate in the several languages of design'. In these descriptions it is apparent that the first three in particular are associated with the ability to transition in to and out of liminal space. Convergent thinking is described as a process where the "questioner attempts to converge on and reveal "facts", While divergent thinking is the mode of enquiry that often occurs in design, where the "questioner is not necessarily concerned with the truthfulness or verifiability of potential answers when posing 
a generative design question'. It is stated that the distinction between the thinking modes is that convergent thinking operates in the knowledge domain while divergent thinking operates in the concept domain. Citing Box (1999) it is concluded that 'engineers must also learn to alternate between inductive processes and deductive processes, using physical understanding or engineering models to inform the experimental approach and then updating their understanding and models based on data'. Design is seen as a flexible process with designers needing to be able to define, evaluate and act, while constantly being able to transition between each of these stages. Liminal space is the transition zone between these stages where divergent-convergent thinking occurs. Divergent-convergent thinking has parallels to the doubled diamond design process proposed by the Design Council, oscillating between open and closed modes as proposed by John Cleese in his 1991 lecture on creativity (1991), as well as the idea of 'T-shaped' individuals proposed by David Guest (1991) and championed by Tim Brown of IDEO, where the vertical component of the ' $\mathrm{T}$ ' represents depth of specific technical knowledge and understanding and the horizontal component represents breadth of diverse interests and influences. In jumping between open and closed modes and between the two parts of the ' $\mathrm{T}$ ' engineering designers demonstrate the ability to flux in an out of liminal space.

Dym (2005) also introduces the concept of engineering languages. Engineering languages include those with which we are familiar (verbal and written), those which we associate with engineering (mathematics and algebraic notation), and those which are perhaps less often bought to mind (graphical representations including sketches and shape grammars), also noted by Stratford (2016). One language implied but not specifically mentioned is that of pseudo-code. From the author's experience of teaching a second year finite element course using Matlab pseudo-code is a valuable form of notation for engineers. Few students at the start of the course were able to articulate, prior to writing a script in Matlab, what stages or processes they wanted the script to achieve. Pseudo-code provides a way of articulating this through the use of sketches and flow charts. It gives an initial framework to what 
is a necessarily structured process. Students may have difficultly undertaking the exercise primarily because it is unfamiliar, not being a language that they have been introduced to before that point on the course, but also because it takes them out of their comfort zone of being presented with problems and methods of solving them. The pseudo-code exercise places students in a liminal state, presenting them with a desired outcome (a functioning script) and the initial parameters. They must therefore engage in problem definition as well as problem solving. In speaking to students following the exercise they on the whole appreciate the challenge. In general the challenging nature of design work has been reported to engage students, forcing them to take control over their own learning, becoming self efficacious learners (Zimmerman 2000), and has been reported to increase student retention rates (Dym et al. 2005).

Dym (1999) presents what is described as a modern as opposed to traditional approach to engineering education. The traditional approach is based on asking what graduating students should know. The modern approach is based on asking what skills and experiences graduating students should have. The comment is made however that 'students have to learn engineering so that they can do design, that is, engineering science is taught to enable our students to be able to do design'. The modern approach is a useful way of thinking about what existing course structures achieve, and opens up some interesting questions beyond the inclusion of design projects within engineering degrees. Questions arise regarding how assessment should be carried out. 'Can exam questions ... be designed to require students to generate concepts by asking generative design questions and then to reason about them by asking deep reasoning questions before offering solutions?' and 'how [can] concept generating be graded, since concepts are neither true or false?'. The EC and ABET guidelines promote the modern approach while leaving considerable scope for engineering departments to decide on the depth of knowledge and understanding appropriate for their curricula and student intake. 
While design projects and courses have to a large extent been accepted and encouraged in later years of degree courses there remains a discourse of views as to whether design exercises are useful in the first two years of engineering courses when student knowledge is not at a sufficient level to allow informed creativity, or complete design thinking to occur. However their inclusion is justified based on studies cited by Dym (2005) showing increased student motivation, with higher retention rates, and greater student involvement and reflection in their own learning. As the concept of liminality can usefully be applied to technical modules and design projects its introduction to students in design teaching in the early years will bring benefits across a degree course.

Graduating engineering students must be capable of design thinking, or informed creativity; but there remain issues with faculty involvement and questions over how desired skill, attribute and experience outcomes can be best achieved (Dym 1994; Dym 1999; Dym et al. 2005).

\section{Design in the Imperial MEng Civil Engineering degree}

In the Department of Civil and Environmental Engineering at Imperial a number of design and construction related projects are included in the MEng degree. In the first and second years students undertake a total of four weeks of Creative Design (consisting of short group design projects varying in scale from individual structures to city wide development) a week long Construction Challenge focusing on project planning and a week of Constructionarium (consisting of hands-on planning and construction of scaled versions of large civil engineering projects (Ahearn et al. 2005)). In the third year students undertake Group Design Projects over a period of six weeks. The Group Design Projects were introduced to the Civil Engineering MEng degree in 1999, while the author has coordinated the projects for six years, since 2011. In the fourth year students undertake an individual dissertation project over a period of around five months. This project may be classified as either a design or research project depending on the nature of the projects offered. This study focuses on 
the Group Design Projects undertaken in the third year under, which are similar to many courses described in a review of capstone courses by Dutson et al. (1994).

The Group Design Projects are organised such that groups are comprised of approximately eight students, with each group undertaking a different project, primarily offered by industrial collaborators in order to provide as realistic an experience as possible. With the year group numbering around 100 students this results in 12 different projects across multiple aspects of Civil and Environmental Engineering. Each group receives an open-ended project brief in the form of a two page document. All groups receive their brief at an initial meeting with the 'client', where the client consists of representatives from the industrial collaborator and a member of academic staff. At the beginning of the projects workshops are held on the engineering design process and group working, architecture in civil engineering, sustainability in civil engineering, enterprise risk management and library research skills. The role of liminality in the design process is highlighted in the first of these.

The groups present and review their projects at weekly critical assessment meetings with the client where instant feedback is provided by the client in the form of a grade as well as direction if required as to what the group might focus on in the week ahead. Additional assessment points include a Pecha Kucha style development presentation at the beginning of the second week, final oral and poster group presentations at the end of the six weeks, and the submission of a feasibility study for each of the projects. Students are also required to keep a log book of their group's activities and for the last two years have been required to submit video diaries for a website $<$ http://groupdesignprojects.org.uk $>$ charting their progress. Collaborating industrial judges, not directly involved with the groups provide additional assessment and feedback at the development and final presentations, while the clients assess the final presentations and the feasibility study in addition to the weekly critical sessions. Further non-assessed feedback is provided through a critique session held with an industry collaborator in the third week and at open review sessions held in the 
second and fourth weeks of the projects, as well as weekly reflective review meetings held by the author with group leaders and liaison officers. Many of the organisational aspects of the Group Design Projects accord with suggestions made by Dym (1994, 1999, 2005) although organisational decisions were taken prior to reading these studies.

The organisation of the Group Design Projects has been developed to take students out of their comfort zone and encourage them to become comfortable with the struggle of breaking in and out of liminal space. The approach taken to continuous assessment and the need to communicate to a variety of audiences deliberately contrasts with the method of assessment favoured on many technical courses, where students linearly progress through defined problems towards pre-determined solutions. Students are required to transition backwards and forwards between different stages of the design process. The use of incomplete project briefs as well as assessed and non-assessed feedback encourages students to view and engage with design as a non-linear iterative process without a well-defined problem and without a pre-determined solution, where they may need to repeatedly loop back, reflect and at times challenge themselves and the client. The overarching aim of the Group Design Projects is for the groups to be challenged in developing designs that they, the client and the judging panel are convinced represent excellent rather than adequate design solutions. To be successful students must become comfortable with fluxing in and out of liminal space as they transition between different stages of the design process. Based on supporting feedback from students, staff, industry collaborators and external assessors (the JBM and external examiners) of the MEng degree the Group Design Projects are successful in achieving this aim. In particular students comment that they find the Group Design Projects extremely challenging, but also extremely rewarding, producing work of a quality that industry clients frequently say they rank alongside that of their employees. It is difficult to provide specific evidence for improvement in design outcomes, corresponding to specific changes to the organisation and assessment of the Group Design Projects, in a before and after fashion. This is because several changes were introduced six years ago, while ongoing changes have been made year 
to year since then. However feedback from academic staff as well as industry collaborators, who have been involved with the projects for several years, suggests that there has been a consistent improvement in both the design outcomes and the approach to design adopted by the students during the projects. Student feedback has also improved throughout this time. While improvement in student feedback will in part be due to the set up of the Group Design Projects, it will also in part be due to improved coordination in the design thread between Creative Design and the Group Design Projects.

Adopting a Pecha Kucha style for the development presentations, with the format of $20 \times 20$ (20 slides with 20 seconds per slide) where the slides auto advance was found to encourage advance preparation of the presentations, higher student satisfaction and prevented the possibility of 'winging it', similar to the findings of other studies (Beyer 2011; Johnson and Christensen 2011). As a result of the success in the application of the Pecha Kucha format to the development presentations the final presentations were changed to follow a 15 minute format with groups having to set auto-advance on all slides, although being allowed to vary the length spent on each slide. The resulting presentations were commented on by the judging panel as being of a higher quality than many tender presentations they had seen in industrial practice. While not intended to place students into a liminal state the use of concise presentation styles presents an unfamiliar challenge where they must decide what information is important to present and what can be discarded.

As well as assessment by the clients and the judging panel a critical part of the Group Design Projects is intra-group peer assessment. This addresses one of the points put forward by Dym (2005) in how group marks allocated to design projects can be translated to individual marks. Peer assessment provides a clear way in which this can be done, which is seen as fair, as the students involved in the design process are best placed to determine which group members over or under perform in comparison to each other. Dochy et al. (1999) reviewed the use of self, peer and co-assessment in higher education concluding that the use of these 
forms of assessment is 'consistent with the need of society for lifelong learners who reflect continuously on their behaviour and the learning processes they experience'. On the Group Design Projects intra-group peer assessment is carried out each week, with each group member submitting scores on a Likert scale from 1-10 for effort and achievement, for each of the other group members, as well as themselves. Continuous peer-assessment causes students to reflect on their own and others performance through the projects. It also helps to prevent students from limiting themselves to one part of the design process, forcing them to step out of their comfort zone to engage with different parts of the design process throughout the projects.

Co-assessment, where students are involved in assessing their own work, is not at present carried out on the Group Design Projects. Self assessment, although carried out as part of the intra-group peer assessment exercise, is not provided as feedback to the students. Dochy et al. (1999) found that the use of self, peer and co-assessment was most effective when they were applied in combination, and when scores were supplied to students by way of feedback. In future years of the Group Design Projects students will be given their intra-group peer assessment scores each week with a comparison against the distribution for the group so that they can compare these to their self assessed scores. It is also proposed that as part of the critical assessment meeting the group should provide a self-assessed score, comparing themselves to other groups, and that a discussion will then take place as to any reasons for differences between this and the score awarded by the client. In practice it has been found that while groups and individuals consider the peer assessment processes to be fair they believe there to be marking discrepancies between different clients. The introduction of aspects of co-assessment along with addition guidelines on how a critical assessment meeting should progress will address these concerns.

With regards to how to convert peer assessment marks into individual marks in combination with the group mark several studies have devised ways in which this can be 
done (Goldfinch and Raeside 1990; Conway et al. 1993). For the Group Design Projects a system of moderating based on the standard deviation across a group in comparison to the standard deviation across all groups with overall alterations limited to $\pm 10 \%$ has been successfully adopted. One advantage of this system is that it does not rely on one group marking to the same mean as other groups, so to some extent avoids the issue observed by Dochy et al. (1999) of high achieving students under-marking and low achieving students over-marking.

A further issue that has been considered in the Group Design Projects is how to assign individuals to groups. This is done through the use of a skills survey including a short Myers-Briggs survey. Groups are assigned based on achieving a uniformity of skills within each group, and having a mix of Myers-Briggs character types. Although there is limited research on the efficacy of alternative methods of allocating groups this approach has proven to be successful with few groups either over-performing on under-performing in comparison to others. It also avoids a problem identified by Brickell et al. (1994) of groups formed from individuals having free choice over which group they work in 'having the poorest attitudes about the course, their instructors, the projects, their classmates, and other criteria'. Students are provided with their Myers-Briggs characteristics which they may then chose to share with their group as a way of accelerating the development of group dynamics. Group working satisfies the Engineering Council guidelines (2014) while also providing clear transferable skills with few engineers working in isolation either in industry or research.

Peer assessment and assigning students to groups and projects were considered as potential sources of concern for the students, however this has not been the case in practice. In conversation the majority of students accept the initial discomfort that working with and assessing group members that they may not have chosen to be placed with, in return for the reward of the greater diversity of perspectives than may be afforded by their normal social groups. The notion of being comfortable with and resolving discomfort is complementary to 
the concept of liminality.

In practice design teaching and learning is an iterative process and one in which both academics and students participate. One reason that some academics may not be keen to engage in more design orientated exercises is that it often requires them to admit to students that they are also in liminal space, thus not conforming to the more tradition perception of the academic as the possessor of knowledge, with the power to pass that knowledge on to students. Through highlighting liminality as a state common to technical and design education, research and industry based design this reticence can be countered.

The Group Design Projects are the first design exercise carried out on the Imperial MEng Civil Engineering degree where students can reasonably be considered to be equipped with the knowledge and understanding required to carry out a feasibility study. Hence while the Group Design Projects are well supported by academic staff the same level of academic engagement may be difficult to achieve for Creative Design and construction related activities carried out in the first and second years. However, it is of note that industry is actively engaged in these exercises and that design in the absence of knowledge and understanding at the start of the degree process, can be used as a driver to push students into taking responsibility for extending their learning through private study, encouraging them to develop as reflective and life long learners, comfortable with fluxing in and out of liminal space.

While teaching and learning through design exercises is becoming increasingly common few educational studies discuss the features of successful design in terms of the concepts and processes involved or the desired learning outcomes, or methods of assessment to reward desired skills and attributes. 


\section{The design process}

Stouffer et al. (2004) provide some guidance on the creative process in design concluding 'Making the strange familiar - accepting creativity as a desirable mindset and attribute of engineers is a tangible and realizable goal that can be readily and actively included in any engineering program'. Liminality provides a concept spanning between technical and design teaching. Studies by Gero and Kannenglesser (2004), followed by Howard et al. (2008) attempt to provide a framework within which the engineering design process can be explained and examined. Gero and Kannenglesser (2004) propose the use of an FBS (FunctionBehaviour-Structure) framework in which the design of an object or system can be broken down into activities associated with Function (what is it for?), Behaviour (what does it do?) and Structure (what is it?). Initially eight process steps linking these activities are defined. The notion of an external world and an interpreted world also containing the expected world are introduced as a sophisticated representation of how the design process is developed. While not expressed in the same words each of the process steps linking the activities can be viewed in terms of divergent-convergent thinking, or the transition in and out of liminal space. Howard et al. (2008) adopt and adapt this model, finding consistency between the design process as described in engineering design and as described in cognitive psychology literature. In particular the study seeks to find indicators of creative as opposed to routine design. Linear models of design are rejected for all but routine design, while comment is made on the 'process of movement between a concept space and a knowledge space'.

Adams et al. (2003) investigate what role reflective practice plays in effective engineering design. It is found that effective engineering design students are far more iterative in their approach to design with many stages of the design process revisited and with additional information being acted on in a 'just in time' manner. The concept of back-talk is introduced as 'when a designer engages in a reflective conversation with the materials, a process that may aid in developing a deeper understanding of the design problem'. It is commented that 
in iterative design 'activities were described as a dialectic interaction across problem and solution spaces and may be a marker of design learning'. This lends itself to comparisons with threshold concepts and the ability to use divergent-convergent thinking to fluctuate in and out of liminal space.

\section{CONCLUSIONS}

The aims of engineering education are dual, needing to provide graduates with both deep knowledge and understanding, but also with the ability to generate innovative design concepts. In research intensive universities these aims do not need to be altered, dependent on whether it is considered that students are being readied for careers in research or industry. New approaches are needed to facilitate these aims without further crowding engineering courses with additional content. Both aims are compatible with the concept of breaking in to and out of liminal space.

Design exercises, particularly in the form of group projects offer a way to achieve this, promoting the view of university students as being at the start of a period of life long learning engaged in reflective practice as they progress into the engineering profession. Threshold concepts, liminal space and divergent-convergent thinking are useful narratives to allow discussion between teachers and learners, as well as researchers and designers, and ultimate progression towards achieving these aims. Group and individual design and research projects have become firm features of third and fourth year MEng degrees in Britain and equivalent degrees elsewhere, although questions remain over how informed creativity and design thinking is best introduced in first and second years. However that use of design exercises in these years can serve to introduce liminality in an applied setting, motivate and retain students in engineering.

Increasing expectations are being placed on engineers. Only through encouraging self motivated life-long learning and reflective practice can we expect to equip graduates with 
the skills, attributes and experience that they will require to assess and address the problems that the world looks to them to solve. Liminal space and the ability to break in and out of it as an essential attribute of successful engineers provides a concept through which engineering educators, researchers and designers can engage in design and technical teaching to enable students and graduates to fulfil the expectations placed on them.

Engineers may be considered to be composites. They are not merely scientists or artists, but may choose from any combination of disciplines that allows them to form, frame and solve the problems presented to them.

\section{ACKNOWLEDGEMENTS}

Thanks go to the academic staff, industry collaborators and students who have participated in the Group Design Projects.

Particular thanks go to Rebecca Naessens for support in coordinating the Group Design Projects, Roger Ridsdill Smith and Chris Trott of Foster+Partners, and Atula Abeysekera who have supported the Group Design Projects for several years, and David Riley of the Educational Development Unit at Imperial College London.

\section{REFERENCES}

Accreditiation Board for Engineering and Technology (2016). "Criteria for accrediting engineering programs, 2016-2017." Available to download from http://www.abet.org/accreditation/accreditation-criteria/criteria-for-accrediting-engineeringprograms-2016-2017/.

Adams, J., Kaczmarczyk, S., Picton, P., and Demian, P. (2007). "Improving problem solving and encouraging creativity in undergraduates." International Conference on Engineering Education - ICEE $200 \%$. 
Adams, R., J., T., and Atman, C. (2003). "Education effective engineering designers: the role of reflective practice." Design Studies, 24, 275-294.

Ahearn, A., Wise, C., McCann, E., and Goring, P. (2005). "Constructionarium: Building to learn." Transactions of the Higher Education Academy, 2(1), 6-16.

Aparicio, A. and Ruiz-Teran, A. (2007). "Tradition and innovation in teaching structural design in civil engineering." Journal of Professional Issues in Engineering Education and Practice, $133,340-349$.

Beyer, A. (2011). "Improving student presentations: pecha kucha and just plain powerpoint." Teaching of Pyschology, 38, 122-126.

Box, G. and Liu, P. (1999). "Statistics as a catalyst to learning by scientific method." Journal of Quality Technology, 31, 1-29.

Brickell, J., Porter, D., Reynolds, M., and Cosgrove, R. (1994). "Assigning students to groups for engineering design projects: a comparison of five methods." Journal of Engineering Education, 83, 259-262.

Chandler, D. (1994). "The transmission model of communication." <http://www.aber.ac.uk/media/Documents/short/trans.html>.

Cleese, J. (1991). "Lecture on creativity." Annotated audio available from $<$ http://genius.com/John-cleese-lecture-on-creativity-annotated $>$.

Conway, R., Kember, D., Sivan, A., and Wu, M. (1993). "Peer assessment of an individual's contribution to a group projects." Assessment and Evaluation in Higher Education, 18, 45-56.

Cousin, G. (2010). "Neither teacher-centred nor student-centred: threshold concepts and research partnerships." Journal of Learning Development in Higher Education, 2, online.

Dochy, F., Segers, M., and Sluijsmans, D. (1999). "The use of self-, peer and co-assessment in higher education: a review." Studies in Higher Education, 24, 331-350.

Dutson, A., Todd, R., Magleby, S., and Sorensen, C. (1994). "A review of literature on teaching engineering design through project-orientated capstone courses." Journal of Engineering Education, 86, 17-28.

Dym (1994). "Teaching design to freshmen: style and content." Journal of Engineering Education, 83, 303-310. 
Dym, C. (1999). "Learning engineering: design, languages, and experiences." Journal of Engineering Education, 88, 145-148.

Dym, C., Agogino, A., Eriz, O., Frey, D., and Leifer, L. (2005). "Engineering design thinking, teaching, and learning." Journal of Engineering Education, 94, 103-120.

Engineering Council (2014). "The accreditation of higher education programes. UK standard for professional engineering competence." Available to download from $<$ http://www.engc.org.uk/>.

Evernden, M., Darby, A., and Ibell, T. (2013). "Engaging students with e-activities." The Structural Engineer, 91(8), 20-23.

Felder, R. and Silverman, L. (1988). "Learning and teaching styles in engineering education." Engineering Education, 78, 674-681.

Furber, A., Crapper, M., Gillie, M., Stratford, T., Bisby, L., Blackford, J., and White, D. (2014). "Innovative learning at the university of edinburgh." Proceedings of the Institution of Civil Engineers - Management, Procurement and Law, 167(1), 13-24.

Gero, J. and Kanneglesser, U. (2004). "The situated function-behaviour-structure framework." Design Studies, 25, 373-391.

Gillie, M., Moore, D., Caron, N., and Mansfield-Williams, T. (2015). "Engineering art: Experiences of an innovative learning week activity." Journal of Professional Issues in Engineering Education and Practice, 141(4).

Goldfinch, J. and Raeside, R. (1990). "Development of a peer assessment technique for obtaining individual marks on a group project." Assessment and Evaluation in Higher Education, 15, $210-231$.

Guest, D. (1991). "The hunt is on for the renaissance man of computing.

Howard, T., Culley, S., and Dekoninck (2008). "Describing the creative design process by the integration of engineering design and cognitive pstcology literature." Design Studies, 29, 160-180.

Ibell, T. (2010). "Learning structural engineering." The Structural Engineer, 88(8), 17-19.

Ibell, T. (2016). "Virtual by design." The Structural Engineer, 94(3), 88-89.

Johnson, D. and Christensen, J. (2011). "A comparison of simplified-visually rich and traditional 
presentation styles." Teaching of Pyschology, 38, 293-297.

Lave, J. and Wenger, E. (2003). Situated learning: legitimate peripheral participation. Cambridge University Press.

Meyer, J. and Land, R. (2003). "Threshold concepts and troublesome knowledge (1): linkages to ways of thinking and practising within the disciplines." Economic and Social Research Council. Teaching and Learning Research Programme.

Meyer, J. and Land, R. (2005). "Threshold concepts and troublesome knowledge (2): epistemological considerations and a conceptual framework for teaching and learning." Higher Education, 49, 373-388.

Perkins, D. (1999). "The many faces of constructivism." Educational Leadership, 57, 6-11.

Sfard, A. (1998). "On two metaphors for learning and the dangers of choosing just one." Educational Researcher, 27, 4-13.

Stice (2004). "Teaching problem solving." $<$ http://wwwcsi.unian.it/educa/problemsolving/stice_ps.html $>$.

Stouffer, W., Russell, J., and Oliva, M. (2004). "Making the strange familiar: creativity and the future of engineering education." Proceedings of the 2004 American Society for Engineering Annual Conference E Exposition.

Stratford, T. (2016). "Experiments in learning design: Creating space for creativity and continuity in design education." The Structural Engineering, August, 14-22.

Zimmerman, B. (2000). "Self-efficacy: and essential motive to learn." Contemporary Educational Psycology, 25, 82-91. 